NASA Technical Memorandum 102443

\title{
Detailed Mechanism for Oxidation of Benzene
}

David A. Bittker

Lewis Research Center

Cleveland, Ohio

May 1990

(AASA-TM-1UP443) JETAILLO MECHANISM EOR
XINATIS\& JF

$N 90-21842$

$$
\begin{array}{ll}
\text { unclas } & \\
53 / 25 & 0200091
\end{array}
$$

\section{N/SN}




\title{
DETAILED MECHANISM FOR OXIDATION OF BENZENE
}

\author{
David A. Bittker \\ National Aeronautics and Space Administration \\ Lewis Research Center \\ Cleveland Ohio 44135
}

\begin{abstract}
A detailed mechanism for the oxidation of benzene is presented and used to compute experimentally obtained concentration profiles and ignition delay times over a wide range of equivalence ratio and temperature. The computed results agree qualitatively with all the experimental trends. Quantitative agreement is obtained with several of the composition profiles and for the temperature dependence of the ignition delay times. There are indications, however, that some important reactions are as yet undiscovered in this mechanism. Recent literature expressions have been used for the rate coefficients of most important reactions, except for some involving phenol. The discrepancy between the phenol pyrolysis rate coefficient used in this work and a recent literature expression remains to be explained.
\end{abstract}

\section{INTRODUCTION}

The major importance of aromatic hydrocarbons in practical engine fuels has made it imperative to increase our understanding of the oxidation mechanism of these compounds. This knowledge is necessary for controlling the combustion and emission characteristics of all gas turbine combustion systems. The simplest aromatic, benzene, has been studied in several recent papers (Venkat et al., 1982, McLain et al., 1979, Kern et al., 1984, Hsu et a1., 1984). A review paper on aromatic hydrocarbon oxidation (Brezinsky, 1986) qualitatively outlined a benzene oxidation mechanism and presented a limited number of experimentally measured profiles for one benzene-oxygen-nitrogen oxidation in 
a high - temperature turbulent flow reactor. A more comprehensive set of concentration profiles for benzene oxidation in the same reactor was recently reported by Lovell et al. (1988).

Ignition delay time measurements (Burcat et al., 1986) have been reported for benzene-oxygen-argon mixtures ignited behind a reflected shock wave. These delay times were measured from pressure versus time profiles over a wide range of starting conditions. The experiments in the last two mentioned papers cover an equivalence ratio range from 0.5 to 2.0 and a temperature range from about 1100 to $1600 \mathrm{~K}$. Pressure varied from 1 to about $7 \mathrm{~atm}$.

This paper presents a comprehensive benzene oxidation mechanism which is used to compute the experimental results given in the latter two papers. In the following sections we present the results of using the new mechanism to compute several concentration profiles for a range of equivalence ratio $(\phi)$ from 0.74 to 1.3. Ignition delay times were also computed for equivalence ratios of $0.5,1.0$ and 2.0 . We show that agreement between experimental and computed trends is generally good. A sensitivity analysis is also presented to demonstrate which reactions have the most significant effect on the computed results. All kinetics and sensitivity computations were performed using the NASA Kinetics and Sensitivity Code, LSENS (Radhakrishnan and Bittker, 1986, 1990). This code implements the decoupled direct method for sensitivity analysis of nonisothermal systems developed by Radhakrishnan (1987).

\section{BENZENE OXIDATION MECHANISM}

The present mechanism is based on the qualltative scheme outlined by Brezinsky (1986), which has been combined with new information presented in several recent papers, as described below. It is also important to use the best possible set of hydrogen-oxygen reactions, which are an important part of all hydrocarbon oxidation mechanisms. The hydrogen oxidation scheme developed 
by Brabbs (1988) was used in these computations. This mechanism was obtained by matching experimental ignition delay times in a shock tube under conditions similar to those being used in the present study. A complete listing of the reactions and rate coefficients used is given in table $I$.

One of the important reactions added to the mechanism of Brezinsky (1986) is

$$
\mathrm{C}_{6} \mathrm{H}_{6}+\mathrm{C}_{6} \mathrm{H}_{5}=\mathrm{C}_{12} \mathrm{H}_{10}+\mathrm{H}
$$

It has recently been studied by Fahr and Stein (1988) and had a significant impact in obtaining agreement between computed and experimental results. As an additional source of $H$ atoms, this reaction increased the importance of the main hydrogen-oxygen branching reaction

$$
\mathrm{H}+\mathrm{O}_{2} \leftrightharpoons \mathrm{OH}+\mathrm{O}
$$

Reaction (102) was one of the important steps in the benzene oxidation for all the experimental conditions studied in this work. Other significant reactions are the attack upon benzene by the radical pool of $0, \mathrm{OH}$ and $\mathrm{H}$ species and also the reaction of phenyl radical $\left(\mathrm{C}_{6} \mathrm{H}_{5}\right)$ with molecular oxygen. These are:

$$
\begin{gathered}
\mathrm{C}_{6} \mathrm{H}_{6}+\mathrm{H} \leftrightharpoons \mathrm{C}_{6} \mathrm{H}_{5}+\mathrm{H}_{2} \\
\mathrm{C}_{6} \mathrm{H}_{6}+\mathrm{O} \leftrightharpoons \mathrm{C}_{6} \mathrm{H}_{5} \mathrm{O}+\mathrm{H} \\
\mathrm{C}_{6} \mathrm{H}_{6}+\mathrm{OH} \leftrightharpoons \mathrm{C}_{6} \mathrm{H}_{5}+\mathrm{H}_{2} \mathrm{O} \\
\mathrm{C}_{6} \mathrm{H}_{5}+\mathrm{O}_{2}=\mathrm{C}_{6} \mathrm{H}_{5} \mathrm{O}+\mathrm{O}
\end{gathered}
$$

As discussed by Brezinsky (1986) and Nicovich et al. (1982), reaction (5) is an addition process whose final products could be either those given or else phenol. The displacement of a ring hydrogen by oxygen would seem to be a simpler procedure than the rearrangement of the adduct to form phenol. Therefore, the reaction has been written as the chain-branching process.

Another important reaction is the decomposition of phenoxy radical

$$
\mathrm{C}_{6} \mathrm{H}_{5} \mathrm{O}=\mathrm{C}_{5} \mathrm{H}_{5}+\mathrm{CO}
$$


The reactions of the cyclopentadienyl radical, $\mathrm{C}_{5} \mathrm{H}_{5}$, have been written to conform to the new experimental results of Lovell et al. (1988). Their results for benzene oxidation in the presence of $\mathrm{NO}_{2}$ indicated that $\mathrm{C}_{5} \mathrm{H}_{5}$ reacts with the radical pool $(\mathrm{O}$ and $\mathrm{OH})$ rather than with molecular oxygen. Therefore the radical plus $\mathrm{C}_{5} \mathrm{H}_{5}$ reactions suggested by Brezinsky (1986) have been used.

The formation and destruction reactions of phenol $\left(\mathrm{C}_{6} \mathrm{H}_{5} \mathrm{OH}\right)$ have been studied in the recent work of He et al. (1988) and Lovell et al. (1989). The latter investigators studied the phenol pyrolysis in the same flow reactor used for the benzene oxidation studies described by Lovell et al. (1988). The mechanism and rate coefficients they report were used as the starting point for selecting the reactions involving phenol. This species is formed in the benzene oxidation by the reverse of reaction (12)

$$
\mathrm{C}_{6} \mathrm{H}_{5} \mathrm{OH}=\mathrm{C}_{6} \mathrm{H}_{5} \mathrm{O}+\mathrm{H}
$$

Reaction (12) exerts an inhibiting effect on the oxidation and the high rate coefficient given by Lovell et al. (1989) strongly supresses the entire benzene reaction by competing for $\mathrm{H}$ atoms with the $\mathrm{H}+\mathrm{O}_{2}$ chain branching reaction. The pre-exponential factor for reaction (12) had to be reduced to one-ninth of Lovell's value. Other reactions of phenol with $\mathrm{H}$ and $\mathrm{OH}$ were taken from Lovell et al. (1989), along with the formation of cyclopentadiene $\left(\mathrm{C}_{5} \mathrm{H}_{6}\right)$ by the reaction of $\mathrm{C}_{5} \mathrm{H}_{5}$ with phenol. They are

$$
\begin{gathered}
\mathrm{C}_{6} \mathrm{H}_{5} \mathrm{OH}+\mathrm{H}=\mathrm{C}_{6} \mathrm{H}_{6}+\mathrm{OH} \\
\mathrm{C}_{6} \mathrm{H}_{5} \mathrm{OH}+\mathrm{H}=\mathrm{C}_{6} \mathrm{H}_{5} \mathrm{O}+\mathrm{H}_{2} \\
\mathrm{C}_{6} \mathrm{H}_{5} \mathrm{OH}+\mathrm{C}_{5} \mathrm{H}_{5}=\mathrm{C}_{6} \mathrm{H}_{5} \mathrm{O}+\mathrm{C}_{5} \mathrm{H}_{6} \\
\mathrm{C}_{6} \mathrm{H}_{5} \mathrm{OH}+\mathrm{OH}=\mathrm{C}_{6} \mathrm{H}_{5} \mathrm{O}+\mathrm{H}_{2} \mathrm{O}
\end{gathered}
$$

Phenyl radical dissoclates into two linear molecules according to the reaction

$$
\mathrm{C}_{6} \mathrm{H}_{5}=\mathrm{C}_{4} \mathrm{H}_{3}+\mathrm{C}_{2} \mathrm{H}_{2}
$$

A newly measured rate coefficient (Braun-Unkhoff et al., 1988) for this pyrolysls was used here. Their expression is valid over a wide temperature 
and pressure range including the conditions for the data being modeled. The measured reaction is actually the intramolecular rearrangement of phenyl to form "linear" $\mathrm{C}_{6} \mathrm{H}_{5}$. This step is assumed to be followed by the very rapid decomposition of that molecule to $\mathrm{C}_{4} \mathrm{H}_{3}$ and $\mathrm{C}_{2} \mathrm{H}_{2}$.

\section{COMPARISON OF COMPUTED AND EXPERIMENTAL RESULTS}

\section{Concentration Profiles}

Lovell et a1. (1988) report composition versus time profiles for benzene-oxygen-nitrogen oxidations at equivalence ratios of $0.74,1.0$ and 1.3. The initial temperature in the flow reactor was $1096 \mathrm{~K}$ and remained essentially constant. The pressure was $1 \mathrm{~atm}$. The exact zero of reaction time is arbitrary, and was taken as the instant of injection of the fuel into the hot oxidant stream. In the computations the reactor was modeled as a constant pressure (l atm) homogeneous batch reaction. For all computations in this work the thermodynamic data are from the NASA Lewis Research Center data base which is part of the NASA Chemical Equilibrium Composition Computer Code of Gordon and McBride (1971). The data for phenyl and phenoxy radicals were reported by Burcat, Zeleznik and McBride (1985). New thermodynamic data for several of the minor species were computed by Bonnie J. McBride of NASA Lewis Research Center. In particular we should mention that properties for ketyl $\left(\mathrm{C}_{2} \mathrm{HO}\right)$ and ketene $\left(\mathrm{C}_{2} \mathrm{H}_{2} \mathrm{O}\right)$ were recomputed using a newly computed heat of formation for ketyl radical of $38.5 \mathrm{Kcal} / \mathrm{mol}$. New thermodynamic properties were also computed for $\mathrm{C}_{5} \mathrm{H}_{5}, \mathrm{C}_{5} \mathrm{H}_{5} \mathrm{O}$, and $\mathrm{C}_{5} \mathrm{H}_{4} \mathrm{OH}$ by $\mathrm{Dr}$. A. Burcat.

Comparisons of computed with experimental profiles are shown in Figs. 1 and 2. Figure 1 shows benzene and carbon monoxide profiles for the three equivalence ratios used and Fig. 2 shows phenol and cyclopentadiene profiles. Quantitative agreement between computed and experimental results is generally better for benzene and carbon monoxide than for phenol and cyclopentadiene at all three equivalence ratios. Figure 1 shows that good quantitative agreement 
is obtained for the benzene and carbon monoxide profiles at $\phi=0.74$. The computed overall rate of the reaction is slightly slower than the experimental one, but the curves have close to the same slope for each species. For $\phi=1.0$ and 1.3 the computed benzene and $C O$ curves show a somewhat faster reaction rate than observed experimentally. The percent difference between computed and experimental slopes ranges from 27 to about 50 for the se two species. This change in the computed net rate from slightly slower to faster than the experimental value as equivalence ratio changes is an indication of an incomplete mechanism. One or more unknown reactions may be unimportant for lean mixtures but exert a significant effect on the reaction rate of richer mixtures. Possible examples of this could be a reaction of benzene with the hydroperoxyl radical or an alternate path for the reaction of benzene with molecular oxygen. The phenol concentration profiles in Fig. 2 show that the computed curves increase faster than the experimental ones for all three equivalence ratios. The best quantitative agreement is obtained for $\phi=1.3$, and all computed curves follow the qualitative trends of the experimental lines. The computed curves for cyclopentadlene show a slower rate of rise than do the experimental lines. The final concentration reached by the computed curves is, however, slightly higher than the value for the experimental curves. In summary, the computed results match all the experimental results qualitatively and there is some good quantitative matching for $\phi=0.74$.

$$
\text { Ignition Delay Times }
$$

The ignition delay times of Burcat et al. (1986) were measured from pressure versus time traces obtained by ignition behind a reflected shock wave. The time interval between shock passage and the first observed "significant" pressure rise was taken as the ignition delay time, $\tau$. The reflected shock conditions reported by Burcat et al. (1986) were first recomputed with 
application of a small correction for attenuation of the initial shock velocity. Only thirty-five of the experimental points reported in Burcat et al. (1986) were used for our comparisons. All data for equivalence ratio of 0.25 were excluded, because examination of the pressure traces showed that the pressure rise was very poorly defined for these weak ignitions. In addition, all ignition delay times less than $100 \mu \mathrm{sec}$ were excluded because pressure disturbances which cause nonuniform heating of the gas behind the reflected shock contribute too high a percentage error to these short ignition delay times (Brabbs and Robertson, 1986). To match the experiment, the computed ignition delay time, $\tau_{p}$, was obtained from each computed pressure versus time plot. The computations were performed assuming a constant volume batch reaction zone behind the shock wave. For each data point a computed ignition delay time was obtained from the computed pressure profile and was defined as the reaction time for a 5 percent rise in pressure. This method gave temperature increases between 30 and $50 \mathrm{~K}$. It was considered to be a satisfactory approximation to the experimental technique, which involved the reading and interpreting of photographic pressure traces.

Four mixture conditions among three equivalence ratios were studied. The experimental conditions for each mixture are given in Table II. Plots of experimental and computed ignition delay time versus the reciprocal of temperature for the four mixtures are shown in Figs. 3 to 6 . The experimental data points are shown for each mixture, as well as a least squares line for each set of computed and experimental data. For a given mixture, each set of data is seen to obey an Arrhenius type equation

$$
\tau \text { or } \tau_{p}=A \exp (\Delta E / R T)
$$

where $R$ is the universal gas constant and $\Delta E$ is an apparent activation energy which measures the temperature dependence of the delay time for a fixed set of initial concentrations. The agreement between experimental and computed 
ignition delay times is good for mixture $3(\phi=1.0$, strong), fair for mixture $2(\phi=1.0$, dilute) and poor to fair for the other two mixtures. For $\phi=0.5$ and the dilute stoichiometric mixture computed values are seen to be consistently higher than the experimental values, whereas the opposite situation occurs with the $\phi=2.0$ mixture. It is significant to observe that, for all mixtures, the computed ignition delay times have values of $\Delta E$ quite close to the experimental values. A summary of the differences between computed and experimental results is given in Table III. Listed here are all the experimental and computed data points and the standard deviations for each mixture. In the case of the strong stoichiometric mixture the standard deviation of the computed results is well within the expected experimental error. For the lean and the rich mixtures, standard deviations are about 45 percent, and the direction of the error is opposite for the two mixtures, as noted above.

In summary, the computations match closely the temperature dependence of all the experimental results and quantitatively predict the delay times for one stolchiometric mixture. The absolute agreement between computation and experiment is fair to poor for the other mixtures. The most serious deficiencies are in predicting delay times of the lean and rich mixtures. For the lean mixture the predicted ignition times are too slow, while for the rich mixture they are too fast. Similar trends with equivalence ratio were obtained for the concentration-proffle computations, as mentioned above. These results again suggest an unknown reaction.

Some new measurements of ignition delay times in reflected-shock heated benzene-oxygen-argon mixtures have recently been reported by Thyagarajan and Bhaskaran (1989). Their method of defining ignition delay time is by detecting first light emission, and may or may not be equivalent to the pressure-rise criterion of Burcat et al. (1986). These new data agree with those of Burcat 
for some conditions but disagree by a factor of 2 to 3 at other conditions. The temperature dependence of the new data is much weaker than that of the Burcat data. The new paper also presents a detalled reaction mechanism which computes their experimental ignition delay time results. However their seventy-reaction mechanism contains no steps involving phenol or cyclopentadiene and is used by the authors to compute concentration versus time profiles only for benzene and acetylene. The latter mechanism differs in several ways from our mechanism. For example, two important reactions are written with different products. Those given for the benzene plus oxygen atom reaction are phenyl and hydroxyl radical rather than phenoxy and $H$ atom used here and recommended by Nicovich et al. (1982). Also, the products of the phenyl plus molecular oxygen reaction are $\mathrm{C}_{2} \mathrm{H}_{3}, \mathrm{C}_{2} \mathrm{H}_{2}$ and $\mathrm{CO}$, rather than phenoxy and oxygen atom as used here and recommended by other investigators (Brezinsky, 1986; Lovell et al., 1988). Also no mention is made in their paper of different collisional efficiencies for the collision partners in the $\mathrm{H}+\mathrm{O}_{2}+M$ recombination reaction. For a mechanism to be valid at temperatures around $1000 \mathrm{~K}$, these collisional efficiencies have to be considered.

In the present work we have used the correlation equation of Thyagarajan and Bhaskaran to compute experimental ignition delay times for several of their mixtures and then used our mechanism to compute these same delay times. Equivalence ratio was varied from 0.5 to 2.0 , pressure from 2 to 10 atm and initial temperature from 1250 to $1750 \mathrm{~K}$. In the worse cases our computed results were about 50 percent lower than the experimental values. However, the computed delay times agreed within 15 percent or better with the experimental results for several cases. Therefore, even though we do not know the exact method by which the delay times of Thyagarajan and Bhaskaran are defined, we 
can say that our present comprehensive mechanism gives computed ignition delay times quite consistent with their experimental data.

DISCUSSION

The mechanism presented here successfully explains all the qualitative trends and matches quantitatively several concentration profiles and ignition delay times measured during the oxidation of benzene. During the development of this mechanism detailed sensitivity analysis computations were performed to determine the rate-controlling reactions and to monitor the effect of rate coefficient adjustments on the computed species profiles. Figure 7 shows normalized sensitivity coefficients for the reactions which control benzene concentration in the flow reactor experiments of Lovel1 et al. (1988). The magnitude of a coefficient is the approximate percent change in the concentration which would be caused by a 1 percent change in the rate coefficient of the given reaction. A negative sign indicates that the direction of the concentration change is opposite to the direction of the rate coefficient change. Results are shown for the lean and rich equivalence ratio, and a reaction time of $50 \mathrm{msec}$ was chosen for this and subsequent figures. Three reactions, independent of equivalence ratio, are seen to be about equally important in controlling the consumption of the fuel; namely reactions ( 8 ), (12) and (102). The first and last of these reactions promotes the oxidation, but reaction (12), which goes in reverse, inhibits the consumption of fue 1 . The information in $\mathrm{Fig} .7$ shows the importance of the competing $\mathrm{H}+\mathrm{O}_{2}$ processes (reactions (102) and (114)), in controlling the oxidation. Both reactions accelerate the oxidation process. In the hydrogen-oxygen system, the $\mathrm{H}+\mathrm{O}_{2}$ recombination inhibits the oxidation because of its chain terminating effect. In the benzene-oxygen system, however, hydroperoxyl radical acts as a chain carrier by reacting with $\mathrm{C}_{6} \mathrm{H}_{5}$ radical to form hydroxyl radical (reaction 
(10)). Figure 7 shows that $O H$ attack on benzene (reaction (6)) is one of the important steps affecting its rate of oxidation. Other reactions involving benzene, such as its pyrolysis and reactions with phenyl and other radicals, are also important in the mechanism. Since we are using a local sensitivity analysis method, we can only pinpoint those reactions for which moderate rate coefficient changes have an effect on the process. Many other reactions would affect the oxidation rate of the fuel if their rate coefficients were very uncertain and were changed by large factors.

Figures 8 to 10 present sensitivity coefficients for carbon monoxide, phenol and cyclopentadiene at the same conditions used in Fig. 7. Results are similar for all species. The same three reactions control all four concentration profiles, and the accelerating effect of the $\mathrm{H}+\mathrm{O}_{2}$ recombination can be seen. Reactions ( 8 ) and (102) have been studied experimentally and their rate coefficlents have small uncertainties. We have only adjusted the coefficient of reaction (8) by a factor of 1.2 to obtain better co profiles. The rate coefficient of reaction (12), the pyrolysis of phenol, is not as well known. For this process we have used an activation energy equal to the endothermicity of the reaction, $88 \mathrm{Kcal} / \mathrm{mol}$, which agrees with the value used by Lovell et al. (1989). The preexponential factor was adjusted to give the best possible fit to all the concentration profiles given by Lovell et al. (1988). The value obtained, $3.0 \times 10^{15}$, is about a factor of nine lower than that used by Lovell et al. (1989). This disagreement is another indication that the mechanism may be incomplete. It should be noted that the Lovell rate coefficient is thermodynamically consistent with the expression given by He et al. (1988) for the reverse of reaction (12). However, the lower A factor used here for reaction (12) glves similar results when modeling both the flow reactor and the shock ignition experiments. Some experimental data are overpredicted and others are underpredicted, depending on equivalence ratio. 
Sensitivity analysis computations have also been performed to find out which reactions were rate-controlling on the ignition process. Figures 11 to 13 show sensitivity coefficients of pressure for three different starting conditions. All three equivalence ratlos are shown and the temperatures used range from 1209 to $1435 \mathrm{~K}$. Under all three conditions, reactions (8), (12) and (102) are the most important ones which affect the ignition delay time as measured by pressure rise. Reactions (8) and (102) accelerate the ignition while reaction (12), which goes in reverse to form phenol, retards the ignition. These are the same reactions that were found to be most sensitive in determining the composition profiles for benzene oxidation at lower temperature in a flow reactor. These computations show that the $\mathrm{H}+\mathrm{O}_{2}$ recombination reaction is one of the rate controlling steps up to a temperature of $1363 \mathrm{~K}$ but decreases in importance as the temperature is raised to $1435 \mathrm{~K}$. As was observed for the flow reactor oxidations, this process accelerates the ignition of the fuel.

This sensitivity analysis shows that it would be difficult to make any simple adjustments of rate coefficients in the hope of getting overall better agreement with the experimental data. Any changes in rate coefficients would improve agreement at one equivalence ratio, but worsen agreement at a different equivalence ratio. One has to search for additional reactions which may resolve the discrepancies. These can be reactions among the normal ground-state species or possibly reactions among excited-state species. Although the latter are not usually considered important at ordinary combustion temperatures, the possibility of excited-state reaction effects cannot be discounted. Reactions involving singlet methylene radical have been suggested as playing a role in hydrocarbon oxidation (Mtller and Bowman, 1989). However, little accurate 
information is known about the thermodynamics and chemical kinetics of excited state species in the benzene-oxygen system, as far as can be determined. So the effect of any excited-state species reactions cannot be investigated at this time. We have, however, made a series of computations with two reactions not used previously. The first one added is the reaction of benzene with hydroperoxyl radical

$$
\begin{gathered}
\mathrm{C}_{6} \mathrm{H}_{6}+\mathrm{HO}_{2}=\mathrm{C}_{6} \mathrm{H}_{5}+\mathrm{H}_{2} \mathrm{O}_{2} \\
\Delta \mathrm{H}=25.6 \mathrm{KCal} / \mathrm{mol}
\end{gathered}
$$

The activation energy was taken as the heat of reaction and the preexponential factor was varied from $1.0 \times 10^{4}$ to $1.0 \times 10^{13}$. Computations showed that this reaction had no effect on any variable profile. In a separate set of computations the reaction between benzene and molecular oxygen was written as an addition and rearrangement process to give products phenoxy and hydroxyl radicals

$$
\begin{gathered}
\mathrm{C}_{6} \mathrm{H}_{6}+\mathrm{O}_{2}=\mathrm{C}_{6} \mathrm{H}_{5} \mathrm{O}+\mathrm{OH} \\
\Delta \mathrm{H}=2.3 \mathrm{KCal} / \mathrm{mol}
\end{gathered}
$$

Both the minimum activation energy of $2.3 \mathrm{Kcal} / \mathrm{mol}$ and a higher value of $10 \mathrm{Kcal} / \mathrm{mol}$ were assumed and the preexponential factor was varied over a wide range. This reaction had a strong accelerating effect on the oxidation. When it was used with the Lovell mechanism for phenol reactions, this reaction overcame the strong inhibiting effect of the high phenol reaction rate coefficients. However, the oxidation process became too fast, and extremely poor concentration profiles and ignition delay times were obtained. This reaction was, therefore, abandoned.

\section{CONCLUDING REMARKS}

A mechanism for benzene oxidation has been presented which explains qualitatively all the observed trends of experimental concentration profiles and ignition delay times over a range of equivalence ratio from 0.50 to 2.0 . 
The computations with this mechanism also quantitatively match much of these data. However, it is clear from our comparisons of computed and experimental results that this mechanism still must be improved to obtain agreement between computation and experiment and resolve questions about the rate coefficients of reactions involving phenol. The need for additional reactions is indicated by the fact that the computations underpredict the experimental results for some equivalence ratios and overpredict them for other equivalence ratios.

\section{ACKNOWLEDGEMENT}

The author gratefully acknowledges the valuable assistance of Bonnie J. McBride, K. Radhakrishnan and A. Burcat during this work.

\section{REFERENCES}

Boehland, T., Temps, F., and Wagner, H.G.G. (1986). Kinetics of the Reactions of Methylene $\left(x^{3_{B}}\right)$ Radicals with Acetylene and Diacetylene in the Temperature Range $296 \mathrm{~K}<\mathrm{T}<700 \mathrm{~K}$. In Twenty-First Symposium (Internationa1) on Combustion. The Combustion Institute, Pittsburgh, PA, pp. 841-850.

Brabbs, T.A. and Musiak, J.D. (1988). Ignition Delay Time Measurements and Proposed Kinetic Model for Hydrogen-Oxygen. NASP Contractor Report 1030 , National Aeronautics and Space Administration, Washington, D.C.

Brabbs, T.A. and Robertson, T.F. (1986). Methane Oxidation Behind Reflected Shock Waves - Ignition Delay Times Measured by Pressure and Flame Band Emission. NASA TM-87268. 
Braun-Unkhoff, M., Frank, P. and Just, T. (1988). A Shock Tube Study on the Thermal Decomposition of Toluene and of the Phenyl Radical at High Temperatures. In Twenty-Second Symposium (International) on Combustion, The Combustion Institute, Pittsburgh, PA, pp. 1053-1061.

Brezinsky, K. (1986). The High-Temperature Oxidation of Aromatic Hydrocarbons. Prog. Energy Combust. Sci. 12, 1 .

Burcat, A., Snyder, C., and Brabbs, T. (1986). Ignition Delay Times of Benzene and Toluene with Oxygen in Argon Mixtures. NASA TM-87312.

Burcat, A., Zeleznik, F.J., and McBride, B.J. (1985). Ideal Gas Thermodynamic Properties for the Phenyl, Phenoxy, and O-BiPhenyl Radicals. NASA TM- 83800.

Cherian, M.A., Rhodes, P., Simson, R.J. and Dixon-Lewis, G. (1981). Kinetic Modelling of the Oxidation of Carbon Monoxide in Flames, In Eighteenth Symposium (International) on Combustion. The Combustion Institute, Pittsburgh, PA, pp. 385-396.

Colket, M.B.,III (1986) The Pyrolysis of Acetylene and Vinylacetylene in a Single-Pulse Shock Tube. In Twenty-First Symposium (International) on Combustion. The Combustion Institute, Pittsburgh, PA, pp 851-864.

Fahr, A. and Stein, S.E. (1988) Reactions of Vinyl and Phenyl Radicals With Ethyne, Ethene and Benzene. In Twenty-Second Symposium (International) on Combustion, The Combustion Institute, Pittsburgh, PA, Pp. 1023-1029. 
Frank, P., Bhaskaran, K.A. and Just, T.H. (1986). Acetylene Oxidation: The Reaction $\mathrm{C}_{2} \mathrm{H}_{2}+\mathrm{O}$ at $\mathrm{High}$ Temperatures, In Twenty-First Symposium (Internationa1) on Combustion, The Combustion Institute, Pittsburgh, PA, pp. $885-93$.

Gordon, S. and McBride, B.J. (1971). Computer Program for Calculation of Complex Chemical Equilibrium Compositions, Rocket Performance, Incident and Reflected Shocks, and Chapman-Jouguet Detonations, NASA SP-273.

He, Y.Z., Mallard, W.G. and Tsang, W. (1988). Kinetics of Hydrogen and Hydroxyl Radical Attack on Phenol at High Temperatures. J. Phys. Chem. 22 , 2196.

Hsu, D.S.Y., Lin, C.Y. and Lin, M.C. (1984). Carbon Monoxide Formation in Early Stage High-Temperature Benzene Oxidation Under Fuel Lean Conditions: Kinetics of the Initiation Reaction, $\mathrm{C}_{6} \mathrm{H}_{6}=\mathrm{C}_{6} \mathrm{H}_{5}+\mathrm{H}$. In Twenthieth Symposium (International) on Combustion. The Combustion Institute, Pittsburgh, PA, pp. $623-630$.

Kern, R.D., Wu, C.H., Skinner, G.B., Rao, V.S., Kiefer, J.H., Towers, J.A. and Mizerka, L.J. (1984). Collaborative Shock Tube Studies of Benzene Pyrolysis. In Twentieth Symposium (International) on Combustion, The Combustion Institute, Pittsburgh, PA, pp. 789-797.

Kiefer, J.H., Mizerka, L.J., Patel, M.R. and We1, H-C, (1985). A Shock Tube Investigation of Major Pathways in the HIgh-Temperature Pyrolysis of Benzene. J. Phys. Chem. 82, 2013. 
Lin, C.Y. and Lin, M.C. (1986). Thermal Decomposition of Methyl Phenyl Ether in Shock Waves: The Kinetics of Phenoxy Radical Reactions. J. Phys. Chem. 20, pp. 425 .

Lin, C.Y. and Lin, M.C. (1987). Kinetics of the Phenyl Radical + Molecular Oxygen Reaction. In Chemical and Physical Processes in Combustion, Fall Meeting, Eastern States Section, Combustion Institute, Pittsburgh, PA, pp. $7 / 1-7 / 4$.

Lovel1, A.B., Brezinsky, K. and Glassman, I. (1988). Benzene Oxidation Perturbed by Nitrogen Dioxide Addition. In Twenty-Second Symposium (International) on Combustion, The Combustion Institute, Pittsburgh, PA, pp. 1063-1074.

Love11, A.B., Brezinsky, K., and Glassman, I. (1989). The Gas Phase Pyrolys is of Phenol. Int. J. Chem. Kinetics $21,547$.

McLain, A.G., Jachimowski., C.J., and Wlison, C.H. (1979). Chemical Kinetic Modeling of Benzene and Toluene Oxidation Behind Shock Waves. NASA TP-1472.

Miller, J.A. and Bowman, C.T. (1989). Mechanism and Modeling of Nitrogen Chemistry In Combustion. Prog. Energy Combust. Sci. 15, 287. 
Miller, J.A., Mitchell, R.E., Smooke, M.D., and Kee, R.J. (1982). Toward a Comprehensive Chemical Kinetic Mechanism for The Oxidation of Acetylene: Comparison of Model Predictions with Results From Flame and Shock Tube Experiments. In Nineteenth Symposlum (International) on Combustion, The Combustion Institute, Pittsburgh, PA, pp. 181-196.

Nicovich, J.M., Gump, C.A. and Ravishankara, A. R. (1982). Rates of Reactions of $O(3 p)$ With Benzene and Toluene. J. Phys. Chem. $86,1684$.

Nicovich, J.M. and Ravishankara, A.R. (1984). Reaction of Hydrogen Atom With Benzene: Kinetics and Mechanism. J. Phys. Chem. 88, 2534.

Radhakrishnan, K. (1987). Decoupled Direct Method For Sensitivity Analysis in Combustion Kinetics. In Advances in Computer Methods For Partial Differential Equations VI, R. Vichnevetsky and R.S. Stepleman, International Association for Mathematics and Computers in Simulation, New Brunswick, NJ, pp. 479-486.

Radhakrishnan, K. and Bittker, D.A. (1986). GCKP86 - An Efficient Code For General Chemical Kinetics and Sensitivity Analysis Computations. Proceedings of Fall Meeting of Combustion Institute, Eastern Section, Pittsburgh, PA, pp. $46-1$.

Radhakrishnan, K. and Bittker, D.A. (1990). LSENS - An Efficient General Chemical Kinetics and Sensitivity Analysis Code for Gas Phase Reactions. NASA RP- , in preparation. 
Slagle, I.R. and Gutman, D., (1986) Kinetics of the Reaction of Propargyl $\left(\mathrm{C}_{3} \mathrm{H}_{3}\right)$ With Molecular Oxygen From 293-900 K. In Twenty-First Symposium (International) on Combustion, Combustion Institute, Pittsburgh, PA, pp. $875-883$.

Thyagarajan, K. and Bhaskaran, K.A. (1989). High Temperature Gas Phase Oxidation Kinetics of Benzene. In Seventeenth International Shock Tube Symposium.

Venkat, C., Brezinsky, K. and Glassman, I. (1982). High Temperature Oxidation of Aromatic Hydrocarbons. In Nineteenth Symposium (International) on Combustion, The Combustion Institute, Pittsburgh, PA, pp. 143-152. 
TABLE I. - BENZENE OXIDATION MECHANISM

\begin{tabular}{|c|c|c|c|c|c|}
\hline Number & Reaction & $\mathrm{cm}^{3}, \stackrel{A}{ }, \mathrm{~mol}, \mathrm{sec}$ & $n$ & $\begin{array}{c}E_{a} \\
\text { cal/mol }\end{array}$ & $\begin{array}{l}\text { Reference and adjustment } \\
\text { factor (A.F.) }\end{array}$ \\
\hline 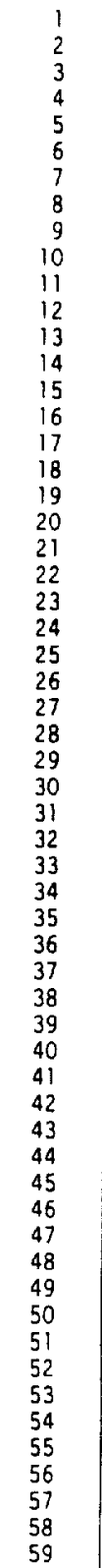 & 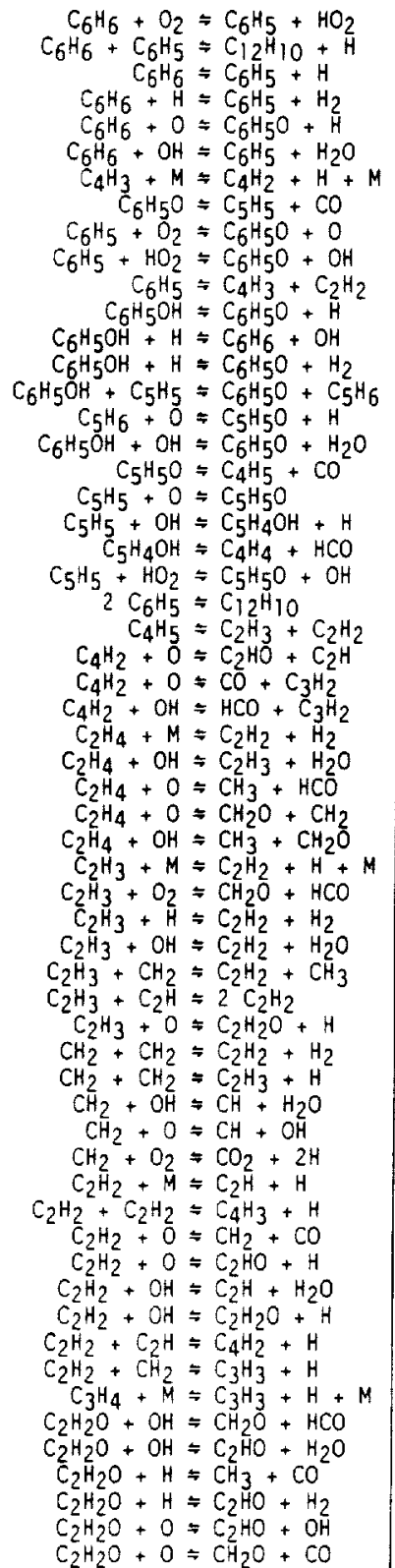 & 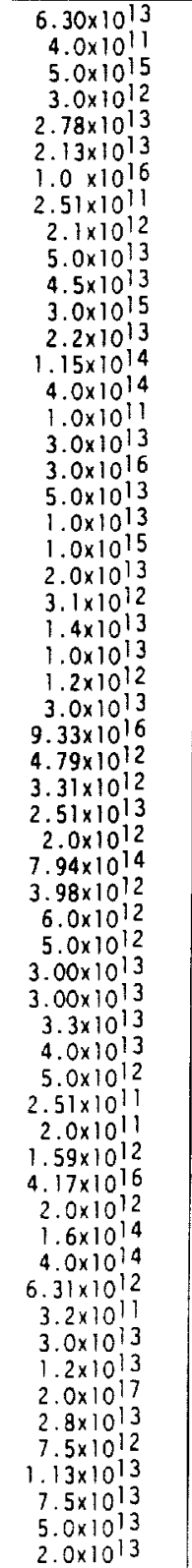 & $\begin{array}{l}0.67 \\
0.68 \\
0.0\end{array}$ & 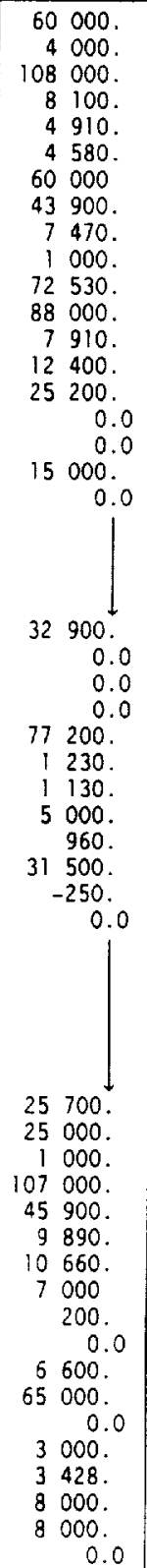 & 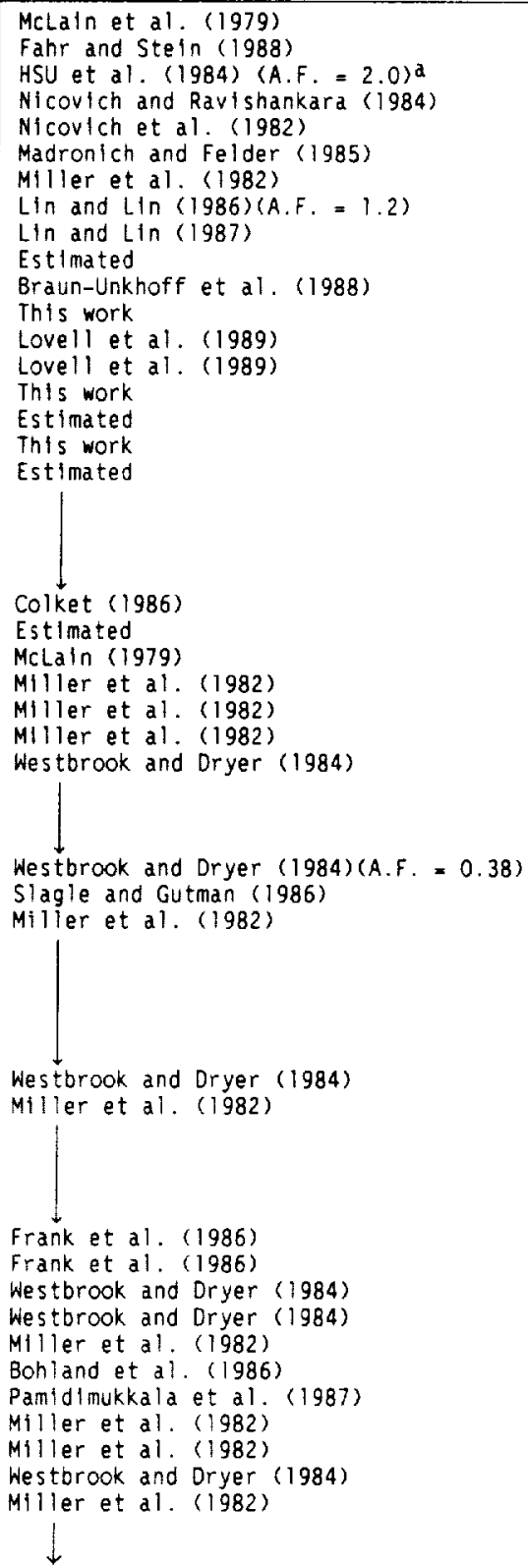 \\
\hline
\end{tabular}


TABLE I. - Concluded.

\begin{tabular}{|c|c|c|c|c|c|}
\hline Number & Reaction & $\mathrm{cm}^{3}, \mathrm{~A}, \mathrm{sec}$ & $n$ & Eal/mol & $\begin{array}{c}\text { Reference and adjustment } \\
\text { factor (A.F.) }\end{array}$ \\
\hline $\begin{array}{l}60 \\
61 \\
62 \\
63 \\
64 \\
65 \\
66 \\
67 \\
68 \\
69 \\
70 \\
71 \\
72 \\
73 \\
74 \\
75 \\
76 \\
77 \\
78 \\
79 \\
80 \\
81 \\
82 \\
83 \\
84 \\
85 \\
86 \\
87 \\
88 \\
89 \\
90 \\
91 \\
92 \\
93 \\
94 \\
95 \\
96 \\
97 \\
98 \\
99 \\
100 \\
101 \\
102 \\
103 \\
104 \\
105 \\
106 \\
107 \\
108 \\
109 \\
110 \\
111 \\
112 \\
113 \\
114 \\
115 \\
116 \\
117 \\
118\end{array}$ & 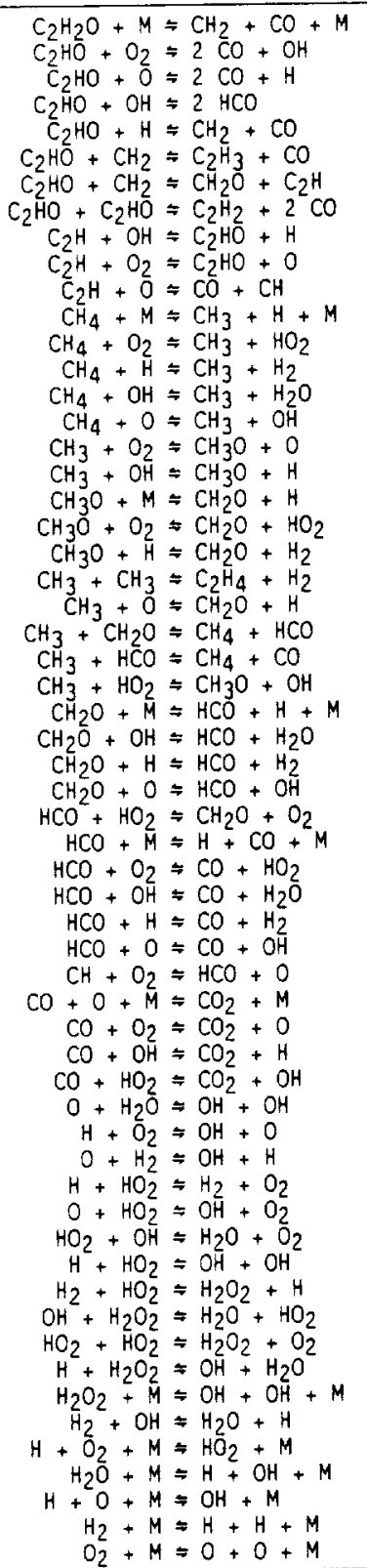 & 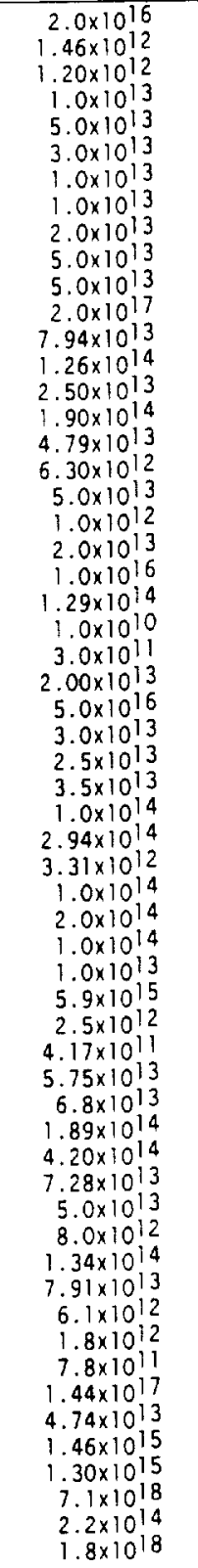 & $\begin{array}{r}1 \\
-1.0 \\
0.0 \\
-1.0\end{array}$ & 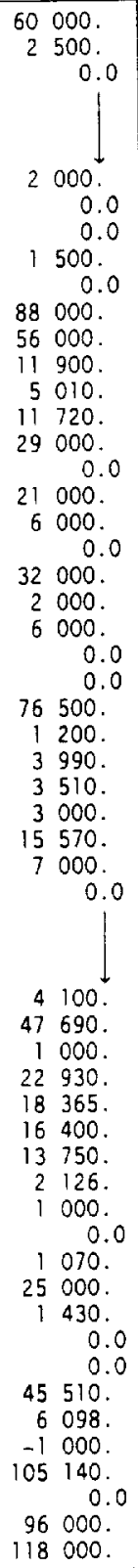 & 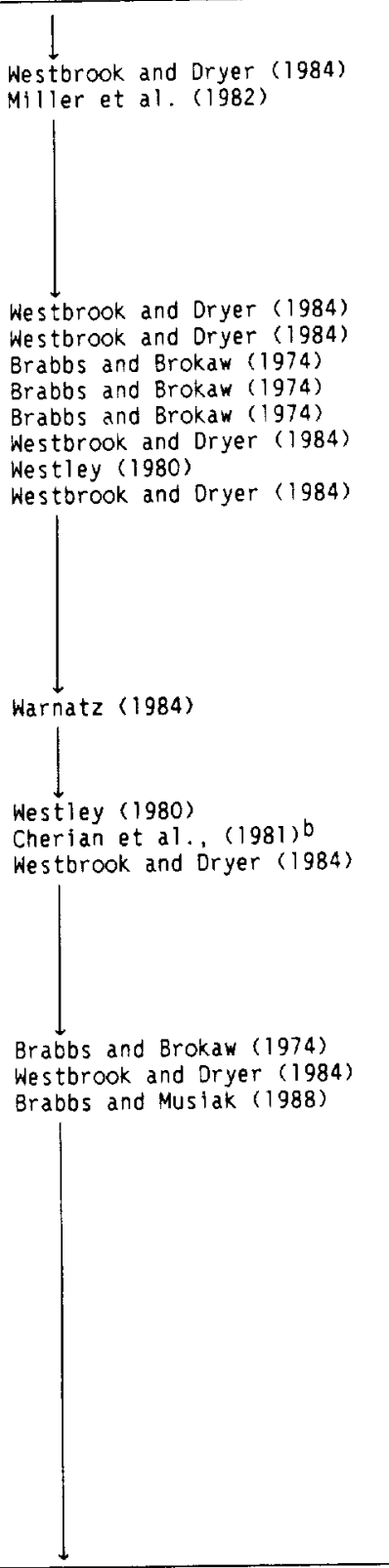 \\
\hline
\end{tabular}

aAdjustment for increased pressure (approximate) from Klefer et al. (1985) used for Ignition-delay computations. bcomputed from reverse reaction rate coefficient and equilibrium constant.

\section{COLLISIONAL EFFICIENCIES}

Reaction 112: $\mathrm{H}_{2}=2.3 ; \mathrm{O}_{2}=0.78 ; \mathrm{H}_{2} \mathrm{O}=6.0 ; \mathrm{H}_{2} \mathrm{O}_{2}=6.6$

Reaction $114: \mathrm{H}_{2}=3.0 ; \mathrm{O}_{2}=0.78 ; \mathrm{H}_{2} \mathrm{O}=6.0 ; \mathrm{H}_{2}=1.3 ; \mathrm{CO}_{2}=7.0 ; \mathrm{C}_{6} \mathrm{H}_{6}=20.0 ; \mathrm{CH}_{4}=5.0$

Reaction 115: $\mathrm{H}_{2}=4.0 ; \mathrm{O}_{2}=1.5 ; \mathrm{H}_{2} \mathrm{O}=20.0 ; \mathrm{N}_{2}=1.5 ; \mathrm{CO}_{2}=4.0 ; \mathrm{C}_{6} \mathrm{H}_{6}=20.0$

Reaction 117: $\mathrm{H}_{2}=4.1 ; \mathrm{O}_{2}=2.0 ; \mathrm{H}_{2} \mathrm{O}=15.0 ; \mathrm{N}_{2}=2.0$

[Rate constant used equals tabulated expression multiplied by adjustment factor.] 
TABLE II. - INITIAL MIXTURE CONDITIONS FOR IGNITION DELAY TIME MEASUREMENTS

\begin{tabular}{|c|c|c|c|c|c|c|}
\hline Mixture & $\begin{array}{c}\text { Equivalence } \\
\text { ratio, } \\
\phi\end{array}$ & $\begin{array}{c}\text { Benzene, } \\
\text { mol \% }\end{array}$ & $\begin{array}{c}\text { Oxygen, } \\
\text { mol \% }\end{array}$ & $\begin{array}{c}\text { Argon, } \\
\text { mol \% }\end{array}$ & $\begin{array}{c}\text { Initial } \\
\text { temperature } \\
\text { range, } \\
\mathrm{K}\end{array}$ & $\begin{array}{c}\text { Initial } \\
\text { pressure, } \\
\text { atm }\end{array}$ \\
\hline 1 & 0.5 & 1.354 & 20.313 & 78.333 & $1209-1345$ & $1.9-2.2$ \\
2 & 1.0 & .516 & 3.868 & 95.616 & $1345-1528$ & $5.6-7.1$ \\
3 & 1.0 & 1.690 & 12.675 & 85.635 & $1283-1435$ & $2.0-2.5$ \\
4 & 2.0 & 1.354 & 5.093 & 93.553 & $1363-1600$ & $2.0-2.6$ \\
\hline
\end{tabular}

TABLE II - COMPARISON OF COMPUTED AND EXPERIMENTAL INGINTION DELAY TIMES

\begin{tabular}{|c|c|c|c|c|c|}
\hline $\begin{array}{l}\text { Mixture number } \\
\text { and description }\end{array}$ & $\begin{array}{c}\text { Initial } \\
\text { temperature. } \\
K\end{array}$ & $\begin{array}{c}\text { Experimental } \\
\text { ignition } \\
\text { delay time, } \\
\text { usec }\end{array}$ & $\begin{array}{c}\text { Computed ignition } \\
\text { delay time, } \\
\mu \mathrm{sec}\end{array}$ & $\begin{array}{c}\text { Percent } \\
\text { difference }\end{array}$ & $\begin{array}{l}\text { Percent } \\
\text { standard } \\
\text { deviation }\end{array}$ \\
\hline $\begin{array}{l}\text { 1. Equivalence } \\
\text { ratio }=0.5 \\
p \cong 2 \text { ATM. }\end{array}$ & $\begin{array}{l}1209 . \\
1227 . \\
1254 . \\
1276 . \\
1291 . \\
1307 . \\
1314 . \\
1345 .\end{array}$ & $\begin{array}{l}878 . \\
743 . \\
435 \\
330 \\
272 \\
185 \\
202 . \\
159 .\end{array}$ & $\begin{array}{r}1200 \\
960 . \\
600 \\
480 \\
390 \\
315 \\
300 \\
209\end{array}$ & $\begin{array}{l}36.7 \\
29.2 \\
37.9 \\
45.4 \\
43.4 \\
70.3 \\
48.5 \\
31.4\end{array}$ & $\begin{array}{c}4.5 \\
--- \\
--- \\
-\cdots \\
--- \\
--- \\
--- \\
--\end{array}$ \\
\hline $\begin{array}{l}\text { 2. Equivalence } \\
\text { ratio }=1.0 \\
\text { (dilute) } \\
p \cong 5-7 \text { ATM. }\end{array}$ & $\begin{array}{l}1345 . \\
1374 . \\
1402 . \\
1412 . \\
1428 \\
1482 \\
1525 \\
1528\end{array}$ & $\begin{array}{l}755 . \\
604 . \\
415 . \\
412 . \\
367 . \\
213 . \\
122 . \\
122 .\end{array}$ & $\begin{array}{c}640 . \\
445 . \\
332 . \\
295 \\
250 \\
147 \\
100 . \\
99 .\end{array}$ & $\begin{array}{l}-15.2 \\
-26.3 \\
-20.0 \\
-28.4 \\
-31.9 \\
-31.0 \\
-18.0 \\
-18.9\end{array}$ & $\begin{array}{c}24.5 \\
-- \\
-- \\
-- \\
--- \\
--- \\
---\end{array}$ \\
\hline $\begin{array}{l}\text { 3. Equivalence } \\
\text { ratio }=1.0 \\
\text { (strong) } \\
p \equiv 2 \text { ATM. }\end{array}$ & $\begin{array}{l}1283 . \\
1290 . \\
1294 . \\
1328 . \\
1355 . \\
1369 . \\
1379 . \\
1405 . \\
1408 . \\
1417 . \\
1435 .\end{array}$ & $\begin{array}{l}750 . \\
613 . \\
607 . \\
490 . \\
303 . \\
287 . \\
291 . \\
198 . \\
189 . \\
178 . \\
151 .\end{array}$ & $\begin{array}{l}760 . \\
700 . \\
660 . \\
440 . \\
320 . \\
280 . \\
258 . \\
208 . \\
178 . \\
163 . \\
130 .\end{array}$ & $\begin{array}{r}1.3 \\
14.2 \\
8.7 \\
-10.2 \\
5.6 \\
-2.4 \\
-11.3 \\
5.1 \\
-5.8 \\
-8.4 \\
-13.9\end{array}$ & $\begin{array}{l}8.9 \\
--- \\
--- \\
--- \\
--- \\
--- \\
--- \\
--- \\
-- \\
--\end{array}$ \\
\hline $\begin{array}{l}\text { 4. Equivalence } \\
\text { ratio }=2.0 \\
p \cong 2 \text { ATM. }\end{array}$ & $\begin{array}{l}1363 \\
1415 . \\
1457 \\
1540 \\
1554 \\
1570 \\
1582 \\
1600\end{array}$ & $\begin{array}{r}1520 . \\
890 . \\
599 \\
274 . \\
243 . \\
211 . \\
157 . \\
154 .\end{array}$ & $\begin{array}{c}780 . \\
440 . \\
320 . \\
150 . \\
130 . \\
110 . \\
100 . \\
90 .\end{array}$ & $\begin{array}{l}-48.7 \\
-50.6 \\
-46.6 \\
-45.3 \\
-46.5 \\
-47.9 \\
-36.3 \\
-41.5\end{array}$ & $\begin{array}{c}45.6 \\
--- \\
--- \\
--- \\
-- \\
-- \\
-- \\
--\end{array}$ \\
\hline
\end{tabular}



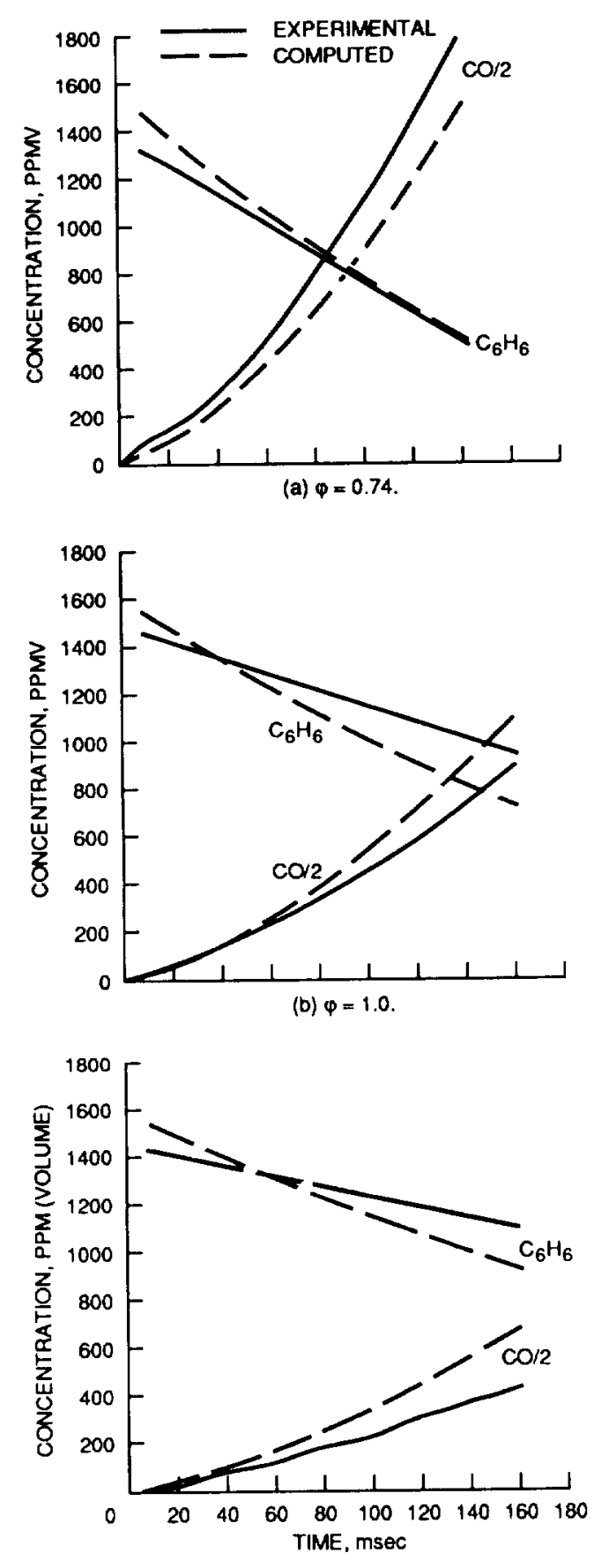

(c) $\varphi=1.3$.

Figure 1. - Benzene and $\mathrm{CO}$ concentration versus time, $T_{0}=1096 \mathrm{~K}$.
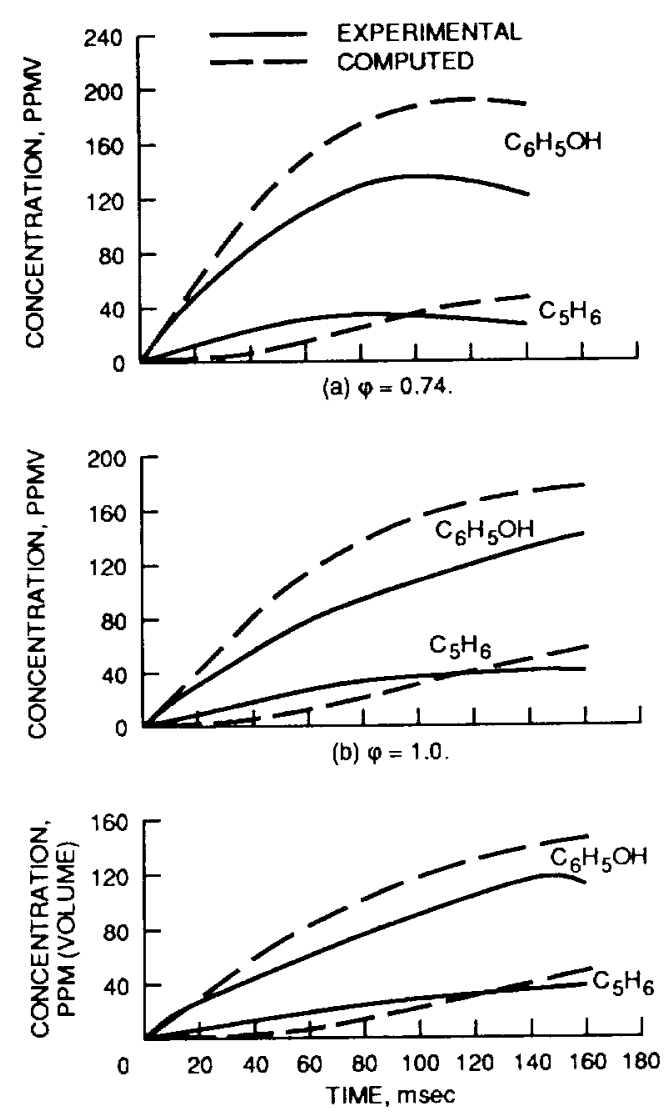

(c) $\varphi=1.3$.

Figure 2. - Cyclopentadiene and phenol concentration versus time, $\mathrm{T}_{0}=1096 \mathrm{~K}$.

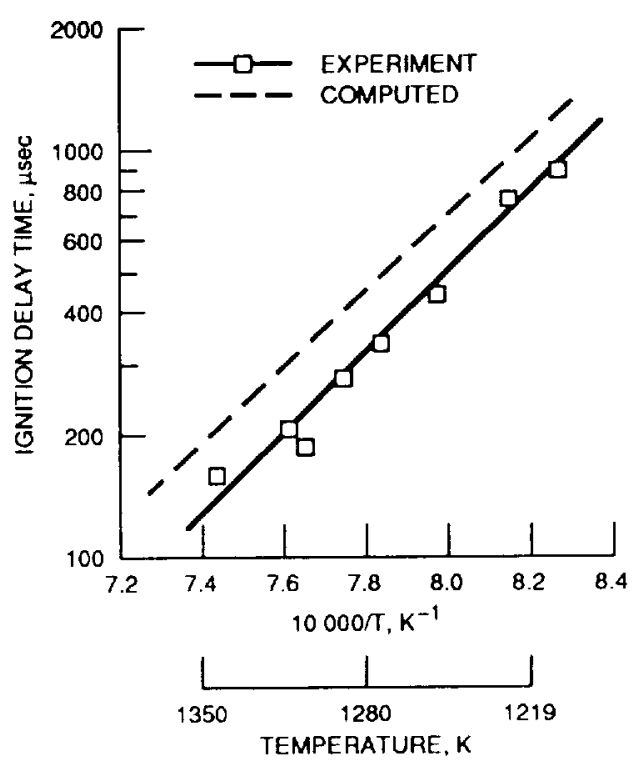

Figure 3. - Benzene-oxygen-argon ignition delay time versus reciprocal of temperature, $\varphi=0.5$. 


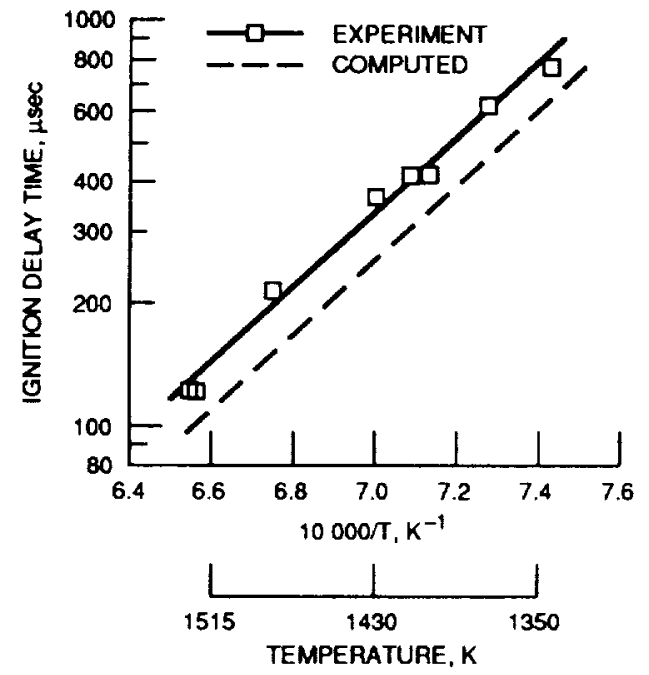

Figure 4. - Benzene-oxygen-argon ignition delay time versus reciprocal of temperature, $\varphi=1.0$, dilute mixture $95.6 \% \mathrm{Ar}$.

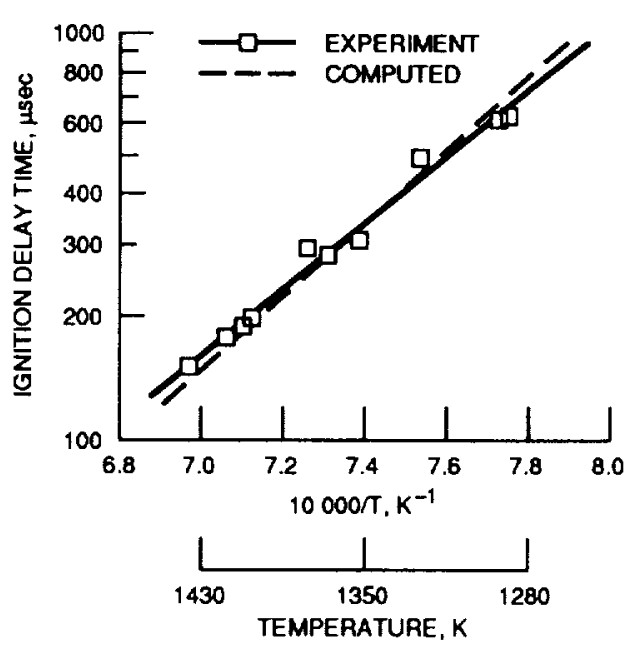

Figure 5. - Benzene-oxygen-argon ignition delay time versus reciprocal of temperature, $\varphi=1.0$, strong mixture $85.6 \% \mathrm{Ar}$.

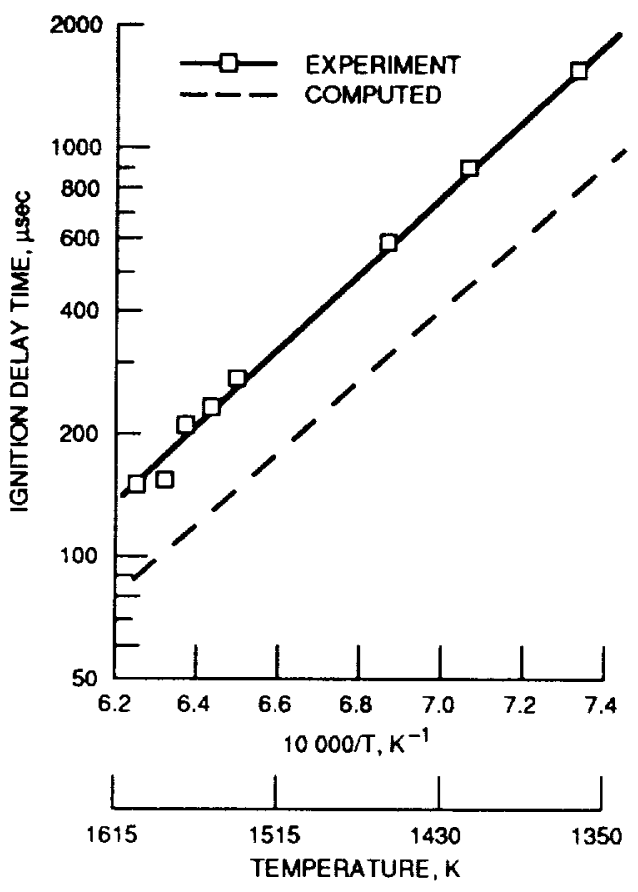

Figure 6. - Benzene-oxygen-argon ignition delay time versus reciprocal of temperature, $\varphi=2.0$. 


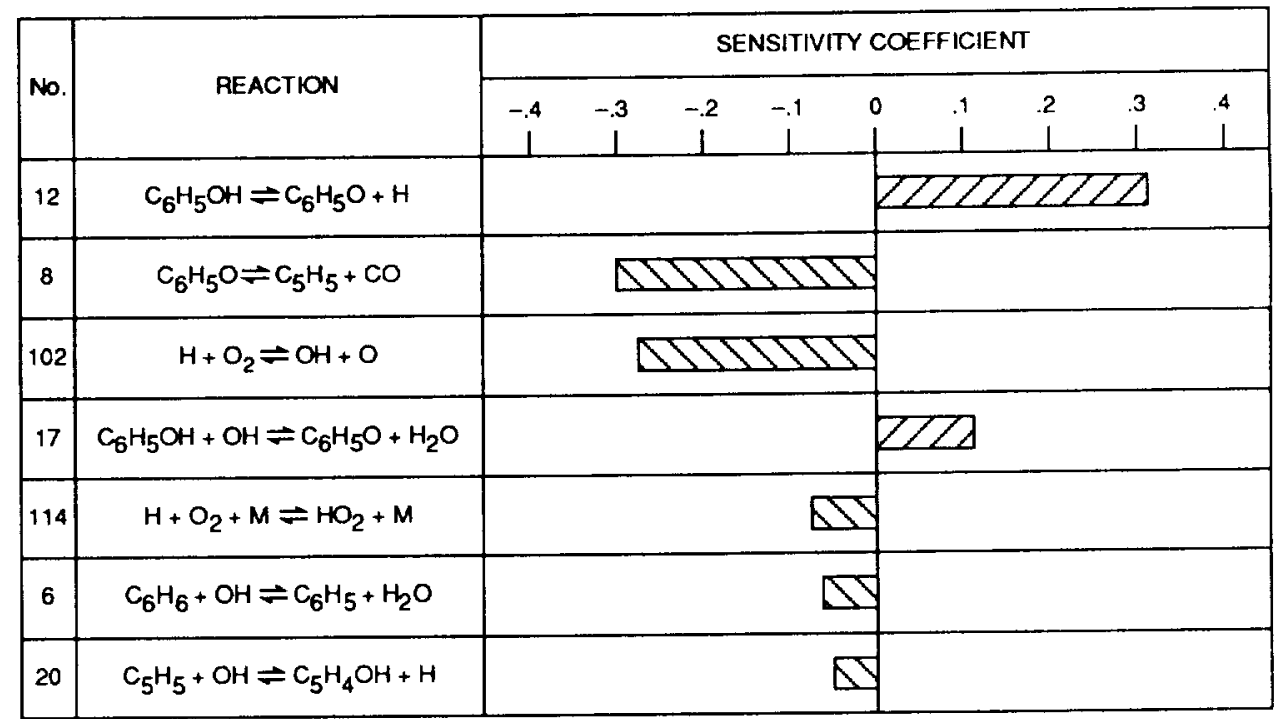

(a) Equivalence ratio 0.74 , temperature $1096 \mathrm{~K}$, time $=50 \mathrm{msec}$.

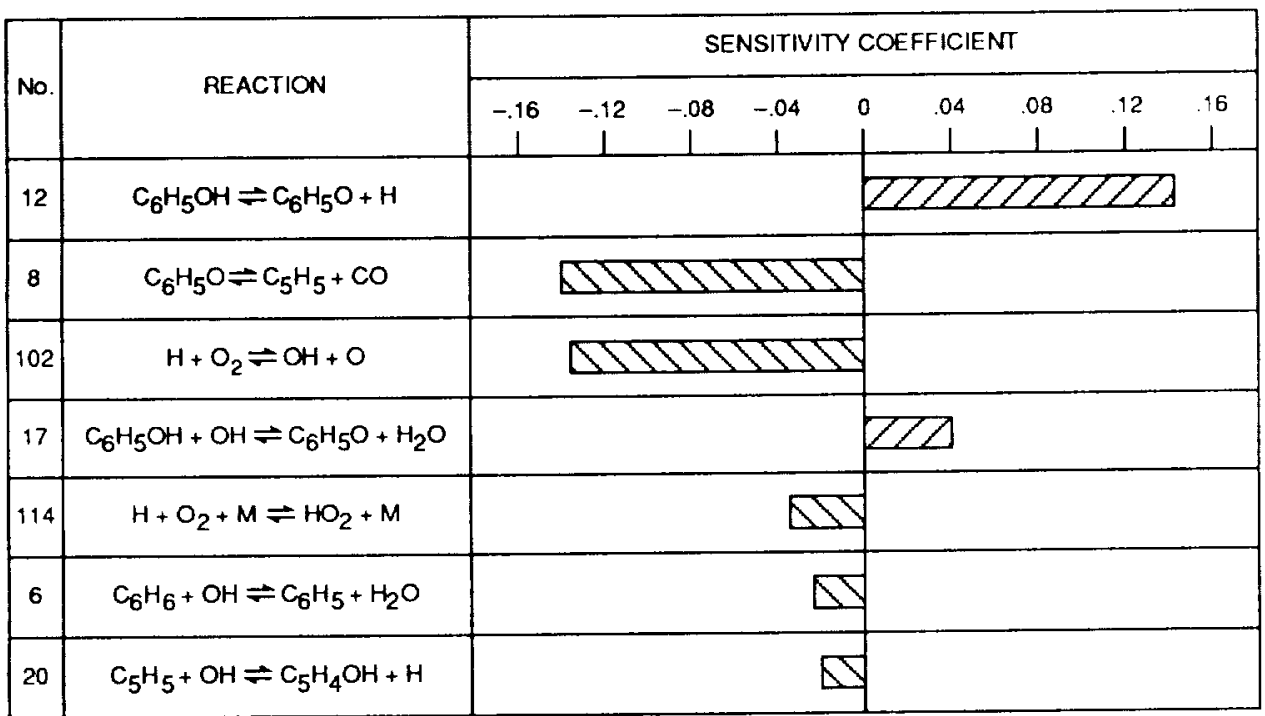

(b) Equivalence ratio 1.3, temperature $1096 \mathrm{~K}$, time $=50 \mathrm{msec}$.

Figure 7. - Sensitivity coefficients for benzene concentration. 


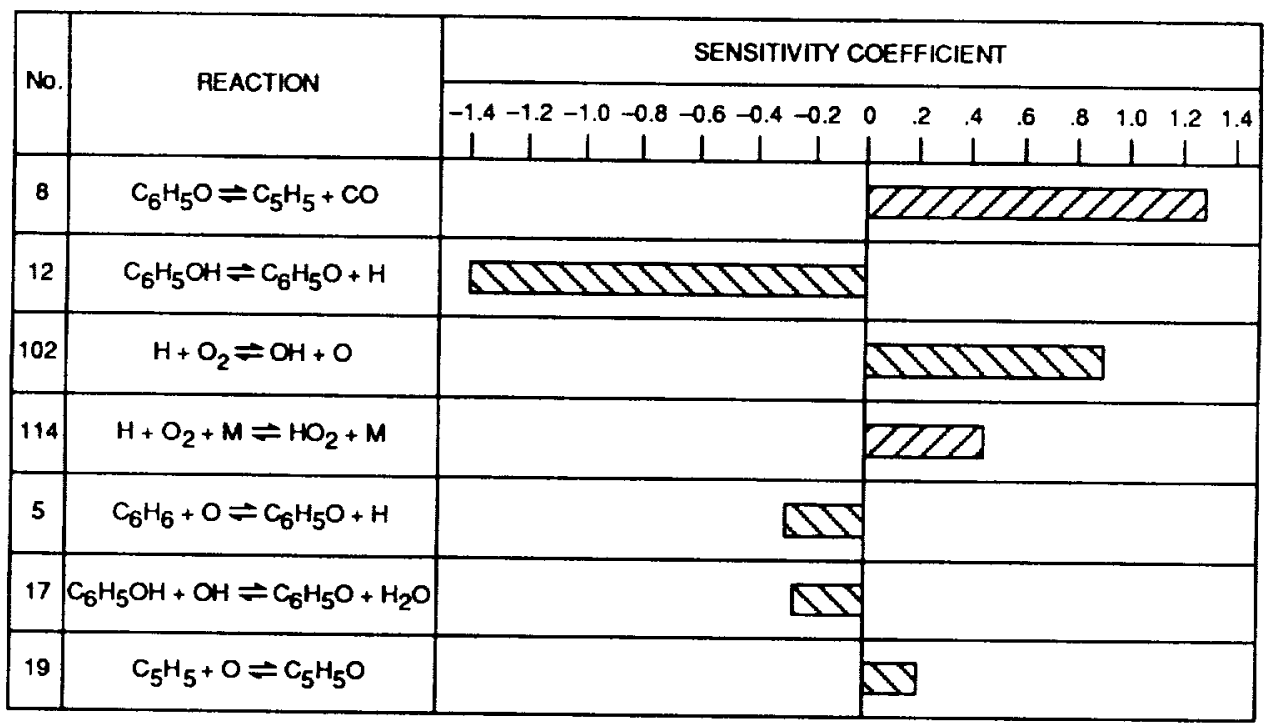

(a) Equlvalence ratlo 0.74 , temperature $1096 \mathrm{~K}$, time $=50 \mathrm{msec}$.

\begin{tabular}{|c|c|c|c|}
\hline \multirow{2}{*}{ No. } & \multirow{2}{*}{ REACTION } & \multicolumn{2}{|c|}{ SENSITIVITY COEFFICIENT } \\
\hline & & 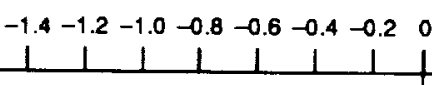 & $\begin{array}{cccccccc}0 & .2 & .4 & .6 & .8 & 1.0 & 1.2 & 1.4 \\
\mid & 1 & 1 & 1 & 1 & 1 & 1 & 1 \\
\end{array}$ \\
\hline 8 & $\mathrm{C}_{6} \mathrm{H}_{5} \mathrm{O}=\mathrm{C}_{5} \mathrm{H}_{5}+C \mathrm{O}$ & & BZZZZZZD \\
\hline 12 & $\mathrm{C}_{6} \mathrm{H}_{5} \mathrm{OH}=\mathrm{C}_{6} \mathrm{H}_{5} \mathrm{O}+\mathrm{H}$ & 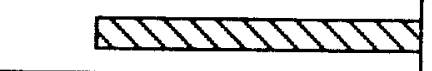 & \\
\hline 102 & $\mathrm{H}+\mathrm{O}_{2} \rightleftharpoons \mathrm{OH}+\mathrm{O}$ & & 5151558 \\
\hline 114 & $\mathrm{H}+\mathrm{O}_{2}+\mathrm{M} \rightleftharpoons \mathrm{HO}_{2}+\mathrm{M}$ & & $Z Z Z$ \\
\hline 5 & $\mathrm{C}_{6} \mathrm{H}_{6}+\mathrm{O} \rightleftharpoons \mathrm{C}_{6} \mathrm{H}_{5} \mathrm{O}+\mathrm{H}$ & $\Delta$ & \\
\hline 17 & $\mathrm{C}_{6} \mathrm{H}_{5} \mathrm{OH}+\mathrm{OH} \rightleftharpoons \mathrm{C}_{6} \mathrm{H}_{5} \mathrm{O}+\mathrm{H}_{2} \mathrm{O}$ & $\Delta$ & \\
\hline 19 & $\mathrm{C}_{5} \mathrm{H}_{5}+\mathrm{O} \rightleftharpoons \mathrm{C}_{5} \mathrm{H}_{5} \mathrm{O}$ & & $\Delta$ \\
\hline
\end{tabular}

(b) Equivalence ratio 1.3 , temperature $1096 \mathrm{~K}$, time $=50 \mathrm{msec}$.

Figure 8. - Sensitivity coefficients for carbon monoxide concentration. 


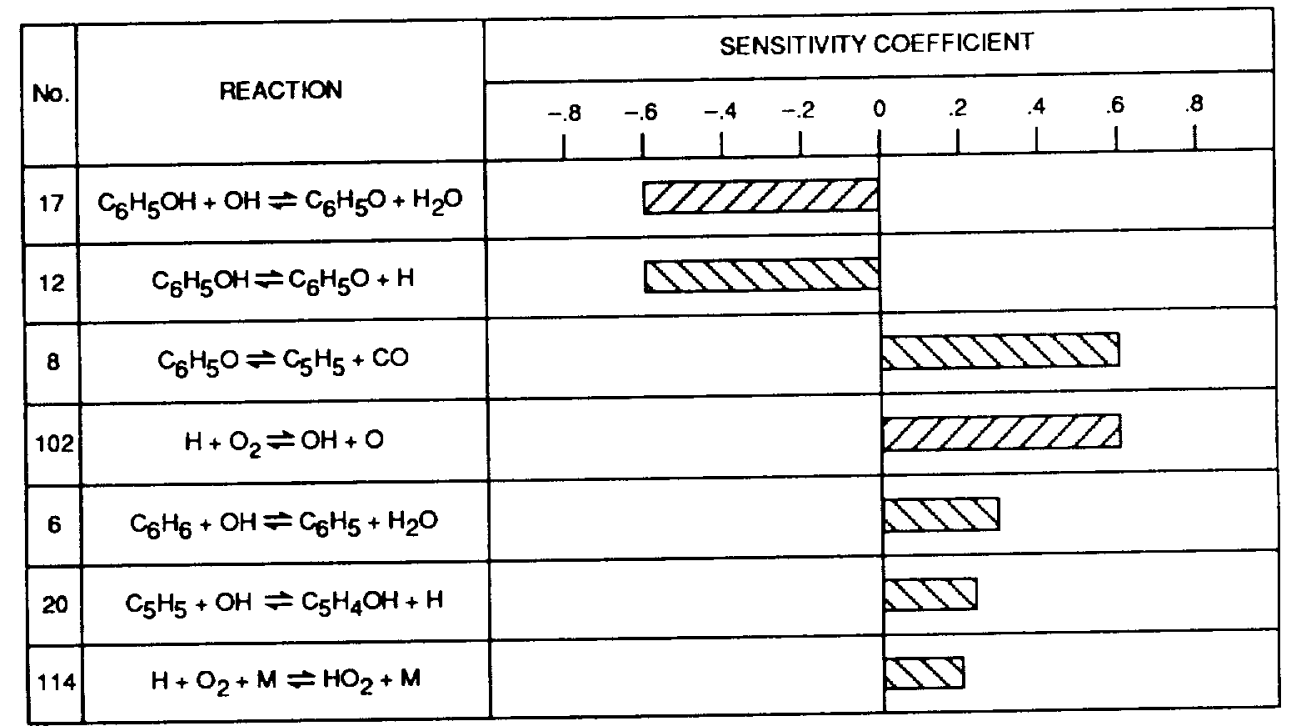

(a) Equivalence ratio 0.74 , temperature $1096 \mathrm{~K}$, time $=50 \mathrm{msec}$.

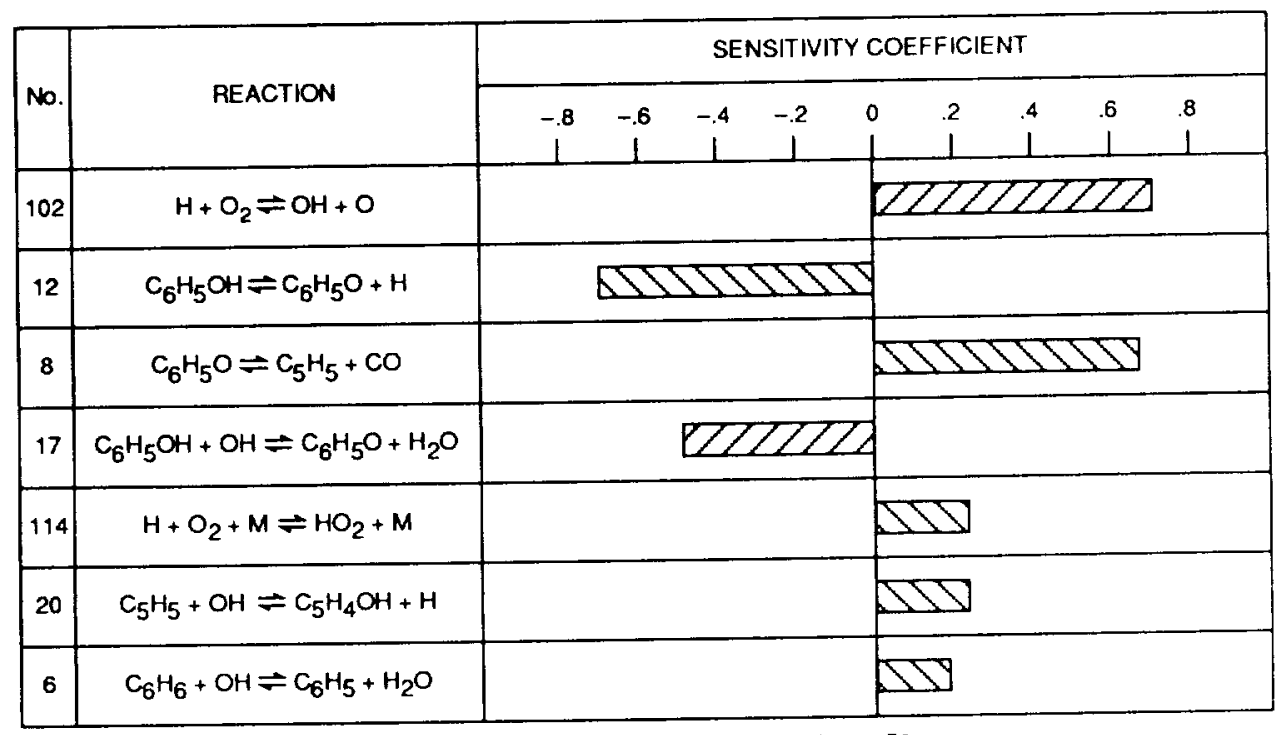

(b) Equivalence ratio 1.3 , temperature $1096 \mathrm{~K}$, time $=50 \mathrm{msec}$.

Figure 9. - Sensitivity coefficients for phenol concentration. 


\begin{tabular}{|c|c|c|c|}
\hline \multirow{2}{*}{ No. } & \multirow{2}{*}{ REACTION } & \multicolumn{2}{|c|}{ SENSITIVITY COEFFICIENT } \\
\hline & & $\mid$\begin{tabular}{cccccc|c|}
-1.2 & -1.0 & -.8 & -.6 & -.4 & -.2 & 0 \\
$\mid$ & $\mid$ & $\perp$ & $\perp$ & $\mid$ & $\mid$ & $\mid$
\end{tabular} & $\begin{array}{ccccccc}0 & .2 & .4 & .6 & .8 & 1.0 & 1.2 \\
1 & 1 & 1 & 1 & 1 & 1 & 1 \\
\end{array}$ \\
\hline 102 & $\mathrm{H}+\mathrm{O}_{2} \rightleftharpoons \mathrm{OH}+\mathrm{O}$ & & BZZZZZZZZZ \\
\hline $\mathbf{8}$ & $\mathrm{C}_{6} \mathrm{H}_{5} \mathrm{O} \rightleftharpoons \mathrm{C}_{5} \mathrm{H}_{5}+\mathrm{CO}$ & & 5015151508 \\
\hline 12 & $\mathrm{C}_{6} \mathrm{H}_{5} \mathrm{OH}=\mathrm{C}_{6} \mathrm{H}_{5} \mathrm{O}+\mathrm{H}$ & 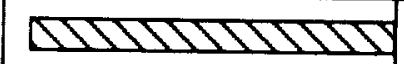 & \\
\hline 15 & $\mathrm{C}_{6} \mathrm{H}_{5} \mathrm{OH}+\mathrm{C}_{5} \mathrm{H}_{5} \rightleftharpoons \mathrm{C}_{6} \mathrm{H}_{5} \mathrm{O}+\mathrm{C}_{5} \mathrm{H}_{6}$ & & ZZZZZZ \\
\hline 17 & $\mathrm{C}_{6} \mathrm{H}_{5} \mathrm{OH}+\mathrm{OH} \rightleftharpoons \mathrm{C}_{6} \mathrm{H}_{5} \mathrm{O}+\mathrm{H}_{2} \mathrm{O}$ & 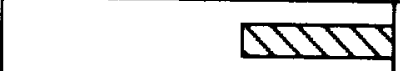 & \\
\hline 6 & $\mathrm{C}_{6} \mathrm{H}_{6}+\mathrm{OH}=\mathrm{C}_{6} \mathrm{H}_{5}+\mathrm{H}_{2} \mathrm{O}$ & & $\Delta 80$ \\
\hline 19 & $\mathrm{C}_{5} \mathrm{H}_{5}+\mathrm{O} \rightleftharpoons \mathrm{C}_{5} \mathrm{H}_{5} \mathrm{O}$ & $\square$ & \\
\hline
\end{tabular}

(a) Equivalence ratio 0.74 , temperature $1096 \mathrm{~K}$, time $=50 \mathrm{msec}$.

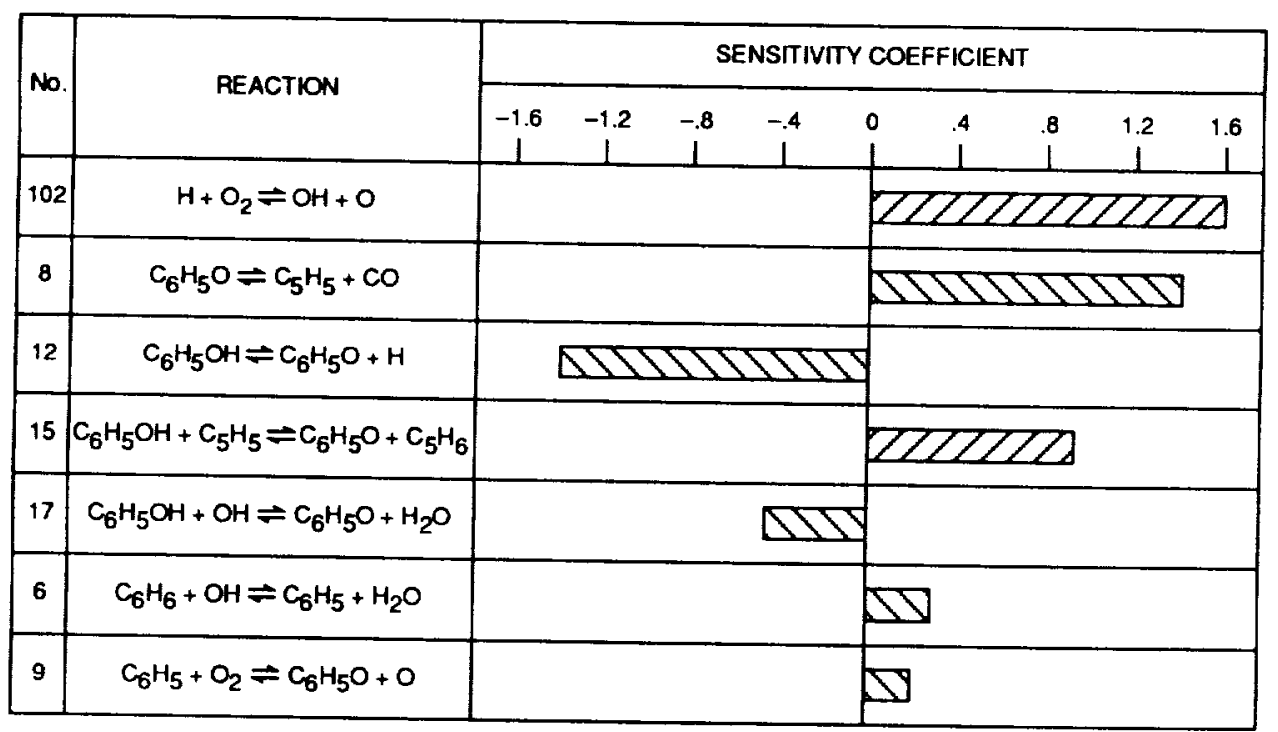

(b) Equivalence ratio 1.3, temperature $1096 \mathrm{~K}$, time $\approx 50 \mathrm{msec}$.

Figure 10. - Sensitivity coefficients for cyclopentadiene concentration. 


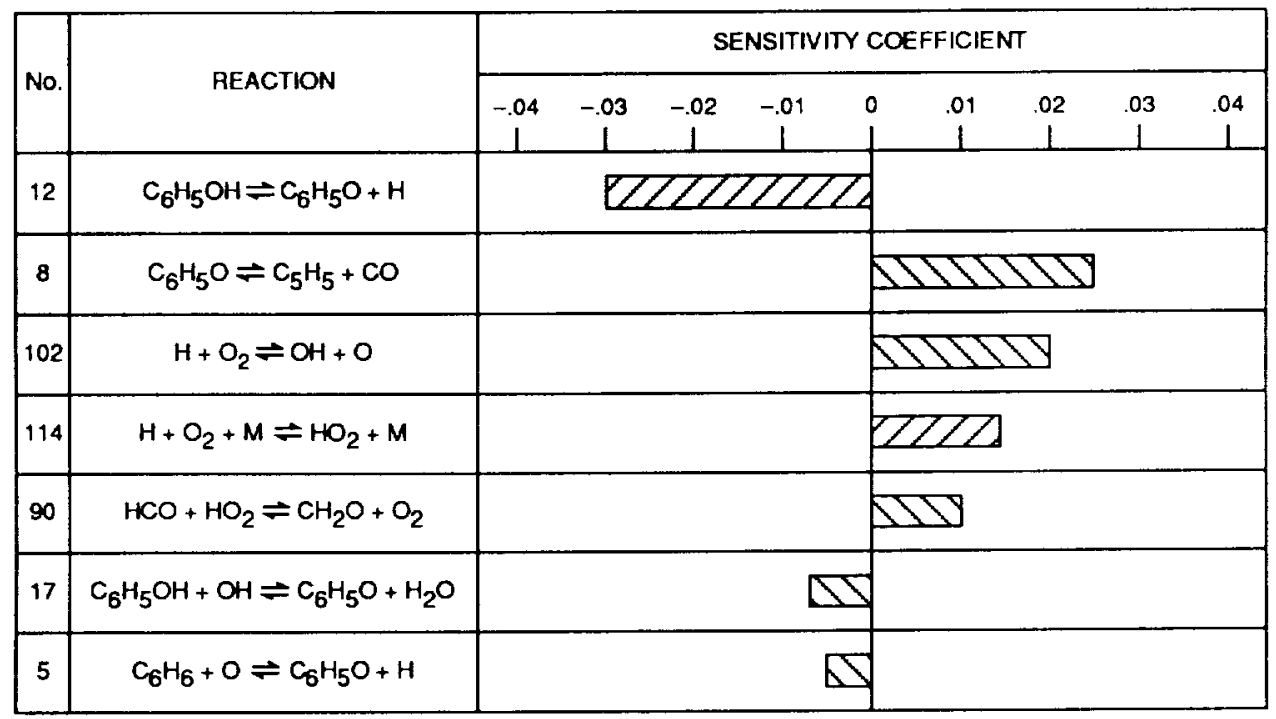

Figure 11. - Sensitivity coefficients for pressure; equivalence ratio 0.5 , temperature $1209 \mathrm{~K}$, time $=900 \mu \mathrm{sec}$.

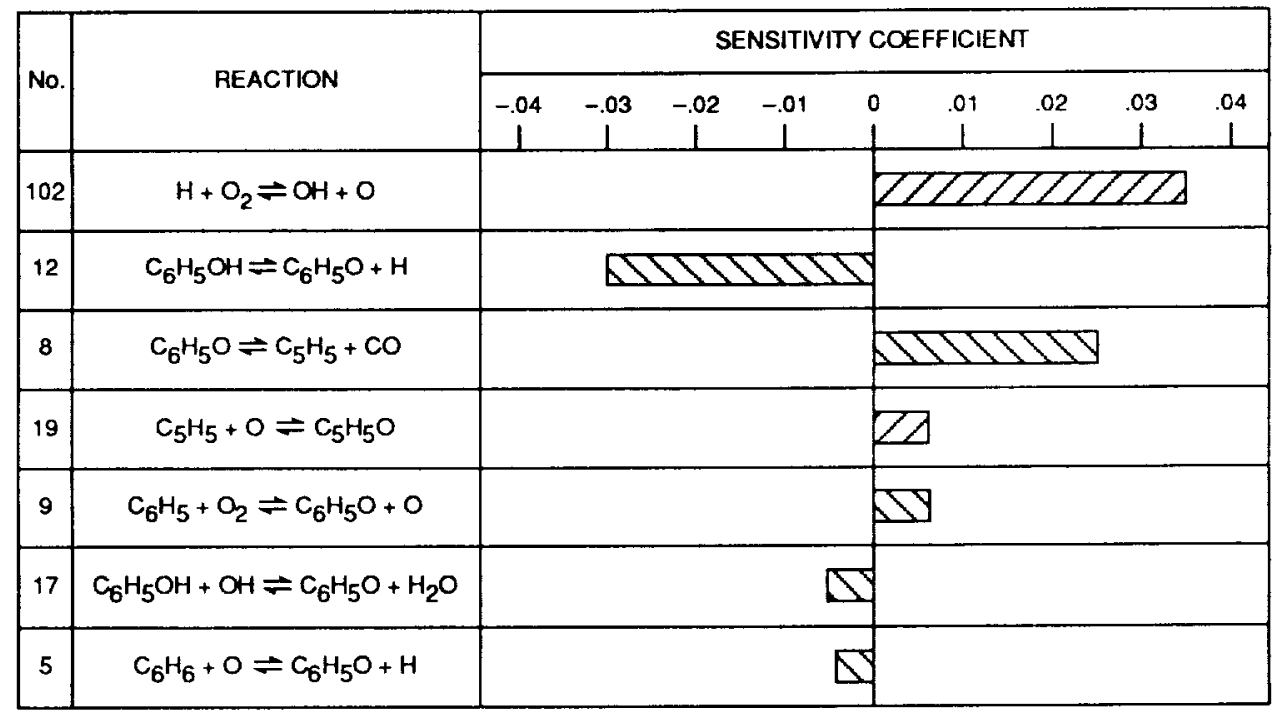

Figure 12. - Sensitivity coefficients for pressure; equivalence ratio 1.0 ( $85 \% \mathrm{Ar}$ ), temperature $1435 \mathrm{~K}$, time $=100 \mu \mathrm{sec}$. 


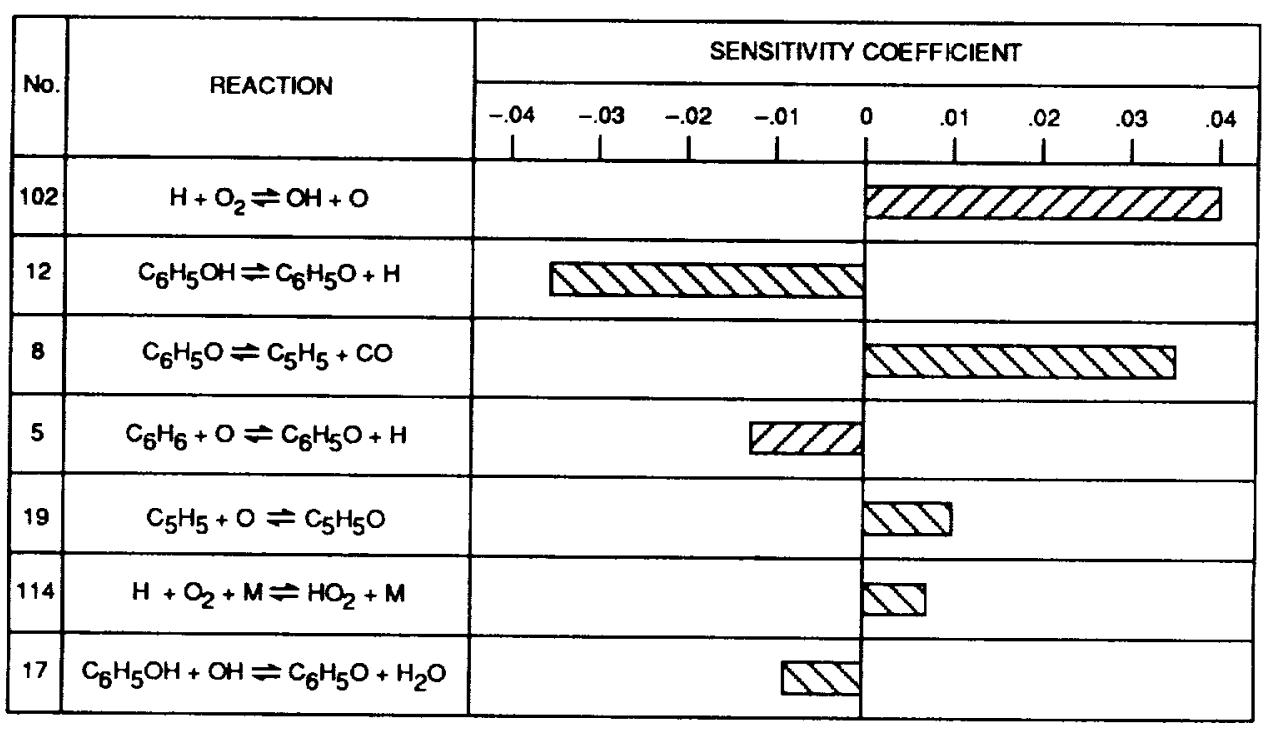

Figure 13. - Sensitivity coefficients for pressure; equivalence ratio 2.0 , temperature $1363 \mathrm{~K}$, time $=600 \mu \mathrm{sec}$. 


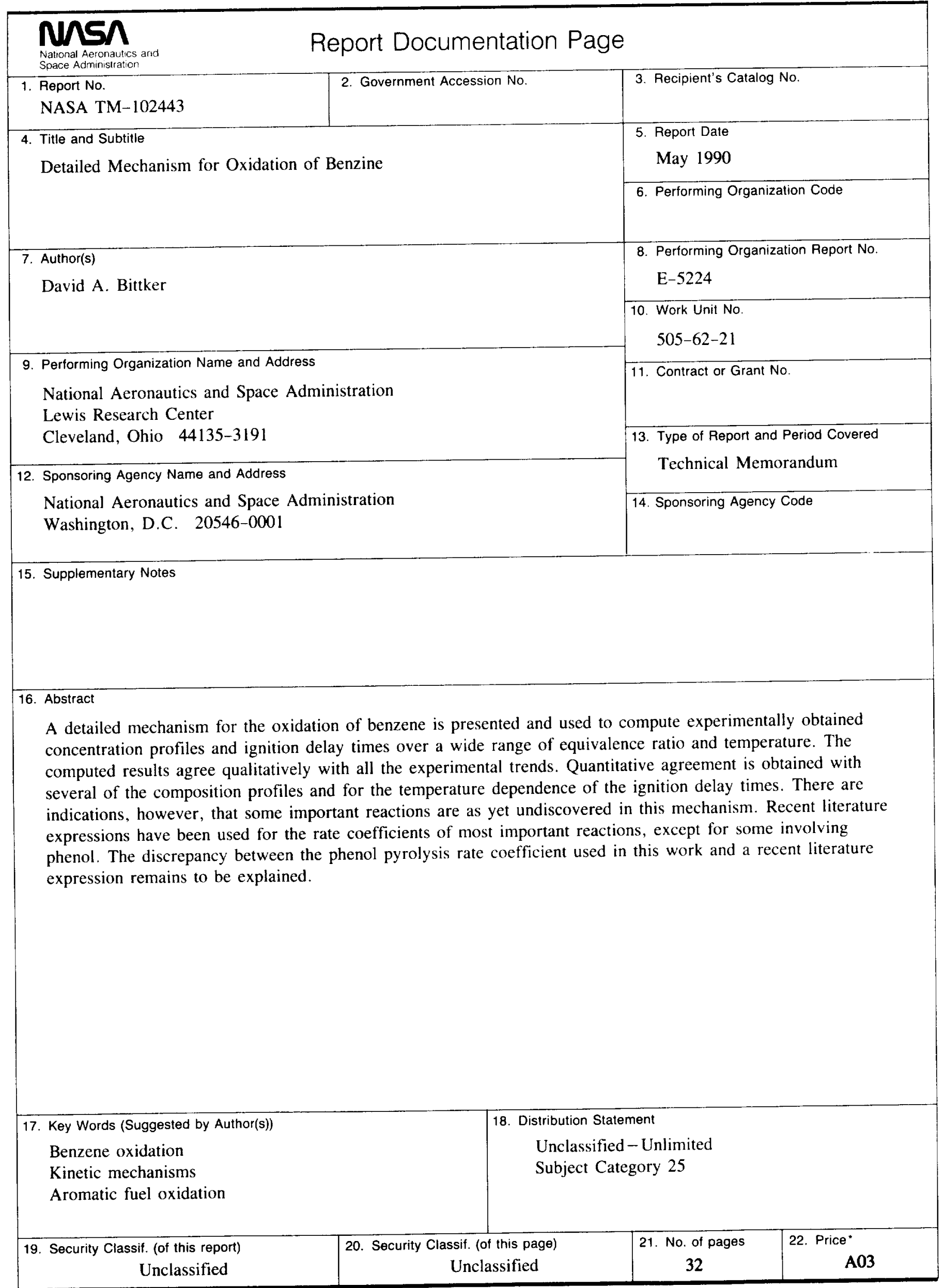




National Aeronautics and

Space Administration

Lewis Research Center

Cleveland, Ohio 44135

Official Bustness

Penalty for Private Use $\$ 300$
FOURTH CLASS MAIL

ADDRESS CORRECTION REQUESTED
|||||

Postage and Fees Pard
Nalionai Aeronaulics and

Space Admumstrittun

NASA 451 